\title{
“BEST-SELLERS" EN ECONOMÍA, UNA LECTURA DESDE LA GEOGRAFÍA ECONÓMICA. DERIVADAS EN EL PAISAJE, EL MEDIO Y LA ORDENACIÓN DEL TERRITORIO
}

\section{BEST SELLERS IN ECONOMY, A READING FROM THE PERSPECTIVE OF ECONOMIC GEOGRAPHY. IMPLICATIONS FOR THE LANDSCAPE, ENVIRONMENT AND SPATIAL PLANNING}

\author{
Manuel J. Marchena Gómez \\ Universidad de Sevilla \\ mmarchena@us.es
}

Recibido: julio, 2014.

Versión final aceptada: enero, 2015.

PALABRAS CLAVE: "Best-sellers", geografía económica, desigualdades territoriales y sociales, instituciones políticas y económicas, medio, paisaje y ordenación del territorio.

KEY WORDS: Best sellers, Economic Geography, territorial and social inequalities, political and economic institutions, environment, landscape and spatial planning.

\section{RESUMEN}

En este artículo se utilizan las ideas de libros y manifiestos superventas editoriales y sus lecciones sobre la Geografía Económica internacional. Se hace un balance de los aportes de la denominada Nueva Geografía Económica y de su relación con los" bestsellers" en economía. Se ha tratado de poner en evidencia las novedades y recurrencias que sobre la Geografía Económica ejercen los autores de moda en Economía. Después de un método de selección atendiendo a criterios de venta electrónica y del interés mostrado por los medios de comunicación, se han elegido tres de éstos por su influencia y temática de interés para la Geografía Económica a escala global. Por fin, se han extraído conclusiones sobre el medio ambiente, el paisaje y la ordenación de territorio. En cualquier caso, existe un denominador común en la lectura de los textos: el rol creciente de las desigualdades territoriales y sociales en el mundo, la importancia de la calidad institucional en la interpretación de las mismas y en general, la necesidad de comunicación entre las ciencias sociales para comprender lo que pasa; más allá de aparatos formales sofisticados e irreales de índole economicista y considerados erróneamente objetos científicos en sí mismos. 


\section{ABSTRACT}

In this paper, the ideas from bestselling books and manifestos and their lessons on International Economic Geography are used. Stock is taken of the contributions of the so-called New Economic Geography and their relationship with the best sellers in economy. Attempts have been made to highlight the innovations and updates in Economic Geography encouraged by authors in vogue in economy. After using a selection method taking into account criteria of electronic sale and media interest, three of them have been chosen due to their influence and subject of interest for Economic Geography on a global scale. Finally, conclusions have been drawn about the environment, the landscape and the spatial planning. In any case, there is a common denominator in the reading of these texts: the growing role of territorial and social inequalities in the world, the importance of the institutional quality in their interpretation and, in general, the need for communication between social sciences to understand what happens, beyond the formal sophisticated and unreal apparatus of an economistic nature which are wrongly considered scientific objects in themselves. 


\section{INTRODUCCIÓN Y MÉTODO.}

La Real Academia de la Lengua Española no tiene aceptada entre sus voces, la de "best-seller"; la reconoce como voz inglesa que se refiere a superventas, a libro o disco de gran éxito y mucha venta. En el bien entendido que mejor o más vendido, no alude necesariamente a la calidad sino a su éxito editorial. Los libros de mucha difusión en Economía, muy divulgados y que son capaces de influir no sólo en el mundo académico, sino que trascienden al ámbito político, social y de los medios de comunicación -pese a que procedan de la Universidad- vienen siendo frecuentes y sus conclusiones u opiniones- incluso, para algunos, novedosos paradigmas- más o menos relevantes, ruidosas o innovadoras se cuelan en el espacio de todo tipo de discursos y hasta decisiones de política económica.

Este trabajo tiene mucho de subjetivo y se soporta en títulos que consideramos, en primer lugar altamente difundidos pese a su construcción científica y génesis universitaria; en segundo lugar, representan en el mundo actual discursos de influencia global, incluido su capacidad polémica; tienen que ver con la Geografía Económica, en tercer lugar; poseen el reconocimiento de superventas por medios de comunicación o soportes de venta electrónico, como cuarta característica; y por fin, en quinto lugar, han sido escogidos por este autor "interesadamente" según su propia visión ideológica de la Geografía Económica en el Siglo XXI.

Por tanto, nos dedicaremos en las próximas páginas a explorar en una selección de "best-sellers" de Economía de los últimos años - tanto libros como autores superventas, ya analizados o ya citados como soporte metodológico a esta particular lectura- para diagnosticar sus influencias desde nuestra subjetiva visión, en el campo de la Geografía Económica; y como describe el título de este artículo, en el paisaje, el medio y la ordenación del territorio, como derivada. Será un análisis de escala global, de escala mundial, marcado por la actualidad y los paradigmas sobre economía general más reiterados hoy día. Fundamentalmente, sobre las versiones más en boga que explican las causas de la desigualdad en la Geografía económica del mundo; de la naturaleza según los manifiestos más al uso, de la prosperidad y la pobreza de las naciones y estados. De posibles nuevos paradigmas en las versiones tradicionales de las grandes escuelas de interpretación económica y de la denominada "Nueva" Geografía económica. Para lo que dedicaremos un epígrafe exclusivo de aproximación teórica.

El método seguido no difiere del utilizado por las revistas de alto impacto -siglas JCRque en el panorama, sobre todo anglosajón, dedican hasta apartados específicos al "Profile". Al estado del arte de una cuestión, es decir al Perfil si seguimos una

\footnotetext{
${ }^{1}$ Estamos aludiendo a revistas como Cities para el perfil de ciudades; a Geoforum o Applied Geography, para enfoques más territoriales o temáticas espaciales y su estado del arte; a World Economy o
}

ISSN: 0212-8594 ISSN-e: 2340-2776.N№ DOI: http://dx.doi.org/10.12795/rea.2015.i32.02

REA 32 (2015):22-48

http://editorial.us.es/es/revista-de-estudios-andaluces 
traducción literal, o a la Revisión de un asunto de interés ya de referencia empírica o territorial, o como es el caso que nos ocupa con una perspectiva más especulativa e ideológica. A saber, las ideas fuerza que subyacen en los autores que influyen en la Geografía Económica del siglo XXI en cuanto a las diferencias en la acumulación de la riqueza; según las grandes corrientes de pensamiento económico. Seguro que no serán todos los que son, pero sí que en una selección a propósito, precisamente al perfil de este trabajo, puedan abarcar los paradigmas de la economía internacional que explican la problemática de la desigualdad en el desarrollo mundial, particularmente.

Desde luego, ésta de la desigualdad económica, es una de los más recurrentes temas de estos momentos, con sus implicaciones en el empleo, la riqueza y la pobreza de las naciones, $y$, la institucionalidad política y económica en la historia de las mundializaciones y en la globalización económica de finales del siglo XX (VV.AA., 2011).De una manera más pormenorizada, explicaremos los pasos efectuados, en este método del "Perfil" de las ideas en el desarrollo de la economía global en el mundo de hoy $^{2}$.

Primero. De cómo identificar un superventas. Hemos utilizado tres portales de venta electrónica: Amazon, Fnac y Casa del Libro. Dos editoriales (del mismo grupo económico) de amplia divulgación en la red: Routledges Economics y Taylor \& Francis. Y la consulta de The Wall Street Journal y The New York Times para el dominio norteamericano y de El País y El Mundo, para medios de comunicación españoles con repercusión internacional. Se han seguido las referencias sobre Economía Global desde principios del siglo XXI a la actualidad. Se ha realizado una estimación cualitativa de títulos y autores más citados e influyentes. En el sentido de encontrar últimas obras de amplio reconocimiento, autores que tienen una reputación de larga trayectoria o que son estimados por sus análisis en los medos de comunicación.

Segundo. De cómo entroncarlos con la problemática de la Geografía Económica. Para ello se ha establecido el criterio de estar refrendados, citados o polemizados por autores que tocan de manera clásica la geografía económica como Buttler (1996), geografía radical como D. Harvey ${ }^{3}$, el premio Nobel de Economía en 2001, G. Akerlof ${ }^{4}$ y la reconocida socióloga (Premio Príncipe de Asturias, 2013) y especialista en

Globalizations para asuntos de economía global; o por fin en geopolítica, a Nation o Public Choice. Particularmente, para el tema aquí analizado las aportaciones del Journal of Economic Geography.

${ }^{2}$ Hemos aprovechado nuestra experiencia personal en la preparación en los grados de Geografía y de Geografía e Historia de la Universidad de Sevilla -durante cuatro años- de materias como Geografía del Mundo y Geografía Regional del Mundo, con un enfoque de escala global y regionalización mundial, basado en las desigualdades económicas.

${ }^{3}$ Sobre la obra de D. Harvey que se adelanta en el tiempo a las consecuencias geográficas y sociales de la Globalización de los mercados, hemos utilizado básicamente los materiales y conversaciones con él en la sede de la Universidad Internacional de Andalucía en Sevilla (2007), en una conferencia sobre Neoliberalismo y desarrollo geográfico desigual en el Curso de ese año sobre "Capital y Territorio".

${ }^{4}$ Se ha utilizado una entrevista con él en la Universidad de Berkeley (California) sobre el asunto en cuestión, en el verano de 2009. 
mundializaciones S. Sassen (2010). Por fin, se ha utilizado la visión ortodoxa del Banco Mundial (2008) y la relativamente reciente reflexión, desde España, de Cuadrado Roura (2012). Se ha tratado aquí de encontrar las referencias más repetidas y el destacado de los autores más influyentes, en especial los premios Nobel P. Krugman, (Nobel de Economía 2008) y J. Stiglitz (Nobel de Economía 2001), con su libro crítico sobre la globalización de (2002).

Tercero. De cómo subrayar una óptica sobre el problema de la desigualdad y sus causas en la economía y la geografía contemporánea. Este enfoque subjetivo que antes considerábamos ideológicamente interesado, se ha basado en el análisis de cuatro monumentales obras y sus referencias bibliográficas. Un auténtico superventas que fue el de M.E. Porter (1990 \& 1998) sobre La Ventaja Competitiva de las Naciones. La aportación D.S. Landes (1999) sobre La Riqueza y la Pobreza de las Naciones y la recientemente publicada visión de la Política y la Historia Económica Contemporánea de J. Fontana (2011). Hemos aprovechado, nuevamente sus referencias bibliográficas y por supuesto y fundamentalmente, sus tesis de cómo abordar desde distintos postulados ideológicos, las causas de las diferencias en la prosperidad económica en las distintas regiones mundiales. En una vertiente geopolítica se ha utilizado, como exponente de un nuevo determinismo geográfico el libro de R. Kaplan (2013): de cómo los mapas condicionan el destino de las naciones, de cómo la situación geográfica de las sociedades humanas prácticamente determinan la historia de los países; una vuelta a la geopolítica y a la importancia estratégica y persistente del mapa (Garfield, 2013).

Antes será necesario exponer una sucinta recensión de lo que preocupa a la nueva geografía económica y cómo se alinean modelos y patrones de pensamiento en distintas escuelas para comprender la desigualdad en el desarrollo económico entre territorios. Donde incluso tiene sitio la teoría, sobre indicios más o menos fundados, de la conspiración global (Rothkopf, 2008). Además aprehender, cómo se ha expandido esta preocupación científica entre los diferentes paradigmas científicos al uso y cómo se utiliza la difusión en manifiestos, medios de comunicación y libros de estos temas en el mundo contemporáneo. ${ }^{5}$

\footnotetext{
${ }^{5}$ Es particularmente estimulante, de cómo la literatura ha interpretado de manera brillante, el paisaje y los elementos geográficos contemporáneamente, nos gustaría citar aquí, una saga de autores que van desde Juan Benet y Mario Benedetti, hasta Italo Calvino y Claudio Magris, y más recientemente Michel Houellebecq. Bestseller tan reputado como el de Picketty (2013), utiliza de forma continuada las novelas realistas y costumbristas del SXIX, para entresacar de su literatura, la naturaleza del capital y las rentas de los personajes, ante la insuficiencia de fuentes estadísticas. Fundamentalmente a H.Balzac en Francia y J. Austen, en Inglaterra.
}

ISSN: 0212-8594 ISSN-e: 2340-2776.№ DOI: http://dx.doi.org/10.12795/rea.2015.i32.02

REA 32 (2015):22-48

http://editorial.us.es/es/revista-de-estudios-andaluces 


\section{PENSAMIENTO TEÓRICO Y ESCUELAS SOBRE GEOGRAFIA ECONÓMICA: PARADIGMAS ACTUALES Y BEST-SELLERS.}

Lo que viene denominándose Nueva Geografía Económica (NGE), ocupa un lugar preponderante en los análisis territoriales desde los años noventa del pasado siglo (Cuadrado Roura, 2012). Uno de sus fundadores Paul Krugman (1999), la consideran en fase de madurez, con lo que puede polemizarse de su capacidad innovadora. Los economistas han cambiado sustancialmente sobre su interés por el espacio geográfico en las cuatro últimas décadas, tanto por el intrínseco desarrollo de la propia ciencia económica (Blaug,1986), como por el divorcio entre geógrafos y economistas que generalmente existió (Richardson, 1975). Minimización del espacio geográfico que sólo se abre a partir del análisis del comercio internacional y las concentraciones industriales, como ya aventuro Marshall desde 1890. La Nueva Geografía Económica ha contribuido claramente a vincular Economía y Geografía, esencialmente en el Análisis Regional y la Planificación Urbana (Behrens y Thisse, 2007).

Como dice Krugman (2000), el replanteamiento del comercio internacional y los efectos de la globalización, abrieron una renovada visión de la Geografía Económica. Es desde la escala global y de las repercusiones de la conexión mundial y asimétrica de mercados y sociedades, desde donde se aprecia precisamente la posibilidad de un análisis territorial de los hechos económicos. Esta visión economicista de la innovación científica en la Geografía Económica (Fujita, 2009), es parte del olvido histórico de los economistas del territorio y de las aportaciones de los geógrafos, que pocas veces alcanzan para explicar estos ámbitos de aproximación global, el calificativo de superventas. En efecto, muchas cosas de la nueva geografía económica son muy antiguas para los geógrafos (Rojas López, 2009) y son bien conocidas para los que se dedican a la denominada Ciencia Regional (R.L. Martín, 2010).

La principal novedad es que las visiones de la geografía económica que se consideran nuevas, no tienen aportación innovadora por las cuestiones que tratan o por los paradigmas que incluyen como directriz de su análisis, sino que son los soportes analíticos-matemáticos, la mayor novedad. Estos aportan un aparente mejor rigor a consideraciones bien conocidas por los geógrafos -localización y deslocalización industrial, descripción y comportamiento de indicadores, centro-periferia, difusión de innovaciones, migraciones y fuerza de trabajo, ubicación del conocimiento... Regiones que pierden y ganan (Benko y Lipietz, 1994)- (Véase en general, Levitt y Dubner, 2007; por cierto otro superventa de alta divulgación entre los iconoclastas sociales). Estas modelizaciones analíticas (Haddad y otros, 1988) sobre temas ya vistos (costes de transporte, polos de desarrollo, movilidad de factores, equilibrios territoriales/económicos. Mírese el clásico de Richardson, 1986) por Hagget, Bunge, o Perroux y Boudeville, en su momento -años 60s y 70s del siglo XX- son citadas por los adalides y bestsellersde la NGE (Bhattacharjea, 2010).

ISSN: 0212-8594 ISSN-e: 2340-2776.N№ DOI: http://dx.doi.org/10.12795/rea.2015.i32.02

REA 32 (2015):22-48

http://editorial.us.es/es/revista-de-estudios-andaluces 
Pero consideramos que existe una segunda y tercera novedad muy entroncada con la Geografía en general y aprovechada en los últimos superventas de Geografía económica: el estudio de series históricas (Historia serial, como diría la escuela francesa desde Braudel, por ejemplo), con una potente base estadística y econométrica y el estudio de casos geográficos (países, estados y regiones) y su comportamiento en el desarrollo económico comparado a lo largo de la historia contemporánea. $\mathrm{O}$ en la reconsideración de la distribución de la riqueza y el empleo (Viveret, 2004), también por tomar un tema clave y desgraciadamente de moda.

En efecto, el interés creciente por las economías de aglomeración que provocan y sostienen crecimiento, la distinción de cinturones agrícolas e industriales, el triunfo de las ciudades (Glaeser, 2011), son tópicos suficientes para justificar la NGE (Fujita, Krugman y Venables, 2000).Es, sin embargo, más llamativo y sobre todo desde la desaparición de la Unión Soviética en 1991, cuando la visión dependentista, centroperiferia, del comercio desigual de la Geografía Económica va perdiendo fuerza en la difusión de las ideas económicas y sus propuestas se mutan por posiciones reguladoras de la globalización (Stiglitz, 2010), o se acercan a la denuncia social reclamando un mayor componente ético y de indignación y rechazo a lo inaceptable en las políticas económicas, sobre todo por la corrupción de la política y la austeridad desigual e inequitativa (Sen y Kliksberg, 2007; Hessel, 2009). Los ciudadanos por encima de los mercados (Hierro, 2011).

En este sentido, si atendemos a las escuelas de pensamiento económico más reconocidas que pendulan entre la defensa a ultranza del libre mercado, el neoliberalismo, la regulación de los mercados y la intervención planificadora, la preocupación de la Nueva Geografía económica, pasa de tener un ámbito local a cómo se comporta y opera un territorio o ciudad en la escala nacional o mundial (Krugmann, 2000). Es decir tomando de partida metodológico una visión más global y que trate de explicar no exclusivamente cómo se relacionan los procesos económicos y el espacio geográfico sino también el "por qué" de dicha relación y sus consecuencias (Cuadrado Roura, 2012). Es decir, con un enfoque de equilibrio general (OCDE, 209). Un superventa en esta materia -Fujita, Krugman y Venables, 2000- nos suministra fundamentos teóricos que permiten mostrar cómo y porqué unas regiones o estados que son muy parecidas o incluso iguales en el punto de partida, pueden acabar diferenciándose como regiones centro/ricas, y regiones periféricas/pobres. Creemos que en este enfoque general (Howit, 2007), versionado ideológica y socialmente, como decíamos más arriba según posiciones en escuelas de pensamiento -hasta llegar a las teorías del crecimiento endógeno (Vázquez, 2007)- estriba el interés de los bestsellers de Geografía Económica en la actualidad.

La explicación a las distintas formas de concentración económica en el espacio geográfico, a diferentes escalas, hasta llegar al nivel global de centro/periferia, o dualismo norte/sur, según escuela ideológica y de pensamiento económico. Los bestsellers actuales -desde el 2010- tratan los problemas del equilibrio general en el 
espacio geográfico, desde bases menos complejas, primero, explicando casos simples y sus variantes (una ciudad, una región. Furió, 1996), pero desde esta escala se procura elevar la comprensión de lo que sucede o podría suceder en la geografía económica global: ya sea en sólo un país, en un conjunto de países o incluso a nivel mundial (MYRO y OTROS, 2008). Para ello se acuden a las series estadísticas históricas y a la evidencia empírica comparada entre regiones mundiales (Fujita y Krugman, 2004).

Para los geógrafos, pensamos, que este giro hacia las ciencias sociales es muy competente, más allá, por un lado de la obsesión por el aparato formal, o de las contribuciones a una visión explicativa más abstracta y compiladora de multitud de variables que, por otro lado superan el ámbito del análisis regional clásico y menos dependiente de la casuística de carácter física o humana de la propia geografía (VV.AA, 2011). Pareciera como puso ya de manifiesto, P. Krugman en la obra citada del año 2000, que los geógrafos tuvimos la sensación de que su campo estaba recibiendo la atención que merecía; particularmente en la geografía económica más tradicional. En cualquier caso el propio Krugman, asumía el escepticismo de los geógrafos por la modelización formal, lo que revela también los límites de los mismos, según este autor (pp. 58/59, de la obra citada). El propio Krugman, luego de la concesión de su Nobel en Economía (2008), prácticamente no ha realizado mayor aportación en la Nueva Geografía Económica o sobre el Comercio internacional, donde fue un pionero reputado. La difusión de conferencias y artículos de opinión en poderosos medios de comunicación, como New York Times o El País, son su mayor preocupación. Hecho también significativo de lo que venimos planteando.

Significa que la modelización de la NGE se apartara básicamente de la realidad? Siguiendo a Storper (2011), las nuevas aportaciones de escala global en la geografía económica, huyen de la dependencia de lo que denomina "primera naturaleza geográfica" (geografía física, localización histórica, singularidades regionales), pero renegando de la lectura del lugar cómo explicación de las economías de aglomeración, se adentran con series estadísticas y modelizaciones formales en interpretaciones institucionales, políticas, sociales, de la desigualdad económica en el espacio geográfico. La nueva geografía económica, según Cuadrado Roura (2012), aporta fundamentalmente las ideas sobre la concentración espacial de la actividad económica y los posibles factores que la provocan. Esto último constituye, el "leit" de los bestsellers actuales de Economía en la materia. Así, desde este enfoque de la NGE, pueden deducirse explicaciones de cómo las fuerzas del mercado conducen a agravar las disparidades territoriales a diferentes escalas. Ello en la tradición de las ciencias sociales, entre ellas la geografía económica, ha derivado hacia recomendaciones de política económica y social, por parte de los propios autores (Cuadrado, 2010).

Los nuevos bestsellers en Geografía Económica han aprendido a distanciarse, como siempre habíamos predicado los geógrafos, de los modelos teóricos y el excesivo formalismo matemático, porque se alejaban del mundo real. Esto ha provocado una inclinación en los trabajos referidos, propia de la tradición geográfica, hacia las 
interacciones espacio-sociedad con una fuerte proclividad a la práctica política y a identificar al menos lo éticamente inaceptable (Véase, el ya clásico Przeworski, 1991), en los procesos de acumulación que adquiere la territorialidad en el desarrollo económico. Se explica el "por qué" de las cosas, según escuela de pensamiento, y ahora además se exige en la composición de un superventas, si lo que sucede en la geografía económica es aceptable, corregible o cambiable. Veremos que a escala global -incluso en los libros de raíz más neoclásica- la NGE aborda los problemas de desigualdad, economía de aglomeración y del esquema centro-periferia, desde la imposibilidad que el mercado pueda solucionarlos de manera exitosa (Ottaviano, 2011). O sobre cómo comprender desde estas bases globalizadoras y de intervención de las políticas, la viabilidad del Estado del Bienestar (Navarro, 2000 y desde donde éste se nutre en Esping-Andersen, 1993).

Pero quisiéramos subrayar que esta producción científica, sobre cómo ver la Nueva Geografía Económica desde la alta difusión editorial ha colocado a la geografía en el corazón de las relaciones entre el desarrollo y las desigualdades regionales. Por su interconexión provocada por la creciente globalización o por las capacidades endógenas de las instituciones, las políticas, la economía y la sociedad de los propios países y regiones (Venables, 2007). En el caso de la Geografía Económica tradicional ${ }^{6}$, la irrupción de estos nuevos planteamientos ha estimulado el desarrollo de un tipo de aproximaciones mucho más formalizadas y menos descriptivas a los temas antes aludidos, que han incluido desde la concentración de la población y la actividad económica, hasta la formación de distritos o cinturones industriales o de nueva agricultura o la localización de servicios y nueva economía del conocimiento y la información (Castells, M. -dir.-,2001). En el siguiente capítulo, profundizaremos en estas ideas a partir de los superventas elegidos al efecto.

\section{SELECCIÓN DE AUTORES Y OBRAS. CONVERGENCIAS Y DIVERGENCIAS EN SUS INVESTIGACIONES.}

En la navegación por la mayor librería del mundo: Amazon.com, se encontrará que entre sus libros de economía más vendidos -los primeros veinticinco- una mayoría son de economistas ortodoxos, considerados como liberales y defensores del libre mercado. Sin embargo, a pesar de la demanda que estos libros tienen, pocos de ellos son publicados por las grandes casas editoriales. El común de lo hallado en esta investigación son éxitos publicados por editoriales universitarias; sin éstas prácticamente la inmensa mayoría de estos superventas, no hubieran sido publicados en el siglo XX. Es ésta la primera constatación que se extrae, incluso cuando se bucea por otros portales (como Fnac y Casa del Libro). De todas maneras, es necesario indicar el sesgo que producen los autores de manifiestos o manuales clásicos de economía

\footnotetext{
${ }^{6}$ Pueden consultarse las Actas de los distintos coloquios del Grupo de Geografía económica y antes de Geografía industrial de la AGE.
}

ISSN: 0212-8594 ISSN-e: 2340-2776.№ DOI: http://dx.doi.org/10.12795/rea.2015.i32.02

REA 32 (2015):22-48

http://editorial.us.es/es/revista-de-estudios-andaluces 
liberal o neoliberal por su agresiva política de ventas (precios muy bajos al respecto de los bestsellers más actuales).

En esta lista encontraremos las conocidas aportaciones de F. Hayek, el número uno, junto a Milton Friedman, Henry Hazzlitt y L. von Mises. Tan interesante como la cantidad de libros sobre la economía de libre mercado, es la ausencia de marxistas y socialistas. Hecho no demasiado inaudito luego del desplome de la Unión Soviética en 1991, y del anterior colapso de su economía a partir de 1970.

Los únicos keynesianos que aparecen son Paul Krugman en el número 15 y el texto de economía de Paul Samuelson, quizás el Manual más utilizado por los universitarios de todo el mundo. No aparecen en estas listas de Amazon, ni Kenneth Galbraith o Lester Thurow, dos reputados keynesianos y defensores de la planificación económica; pese al apoyo de los medios de comunicación.

Al establecerse, una evaluación de las fuentes antes citadas de los libros actuales de economía internacional y global y que atañen a la descripción del mundo desde la perspectiva de la desigualdad económica y sus causas, encontraremos tres títulos de la más reciente actualidad y de los que hemos considerado sus traducciones, en su caso, al castellano. Bestsellers calificados por The Wall Street Journal y The New York Times, como títulos que repasan la Geografía económica y la naturaleza de la Riqueza de las Naciones, y líderes en ventas -para ciencias sociales- por Amazon, en sus respectivos años de edición en la lengua original de su escritura:

Libros $^{7}$ :

1.- Carmen M. Reinhart y Kenneth S. Rogoff, Esta vez es distinto. Ocho Siglos de necedad financiera. Fondo de Cultura Económica, México 2011. 472 pp.

2.- Daron Acemoglu y James A. Robison, Los orígenes del Poder, la prosperidad y la Pobreza. Por qué fracasan los Países, Deusto Ediciones, Barcelona 2012. 589 pp.

3.- Thomas Piketty, Le Capital au XXI siècle, Ed. Seuil, Paris 2013. 969 pp.
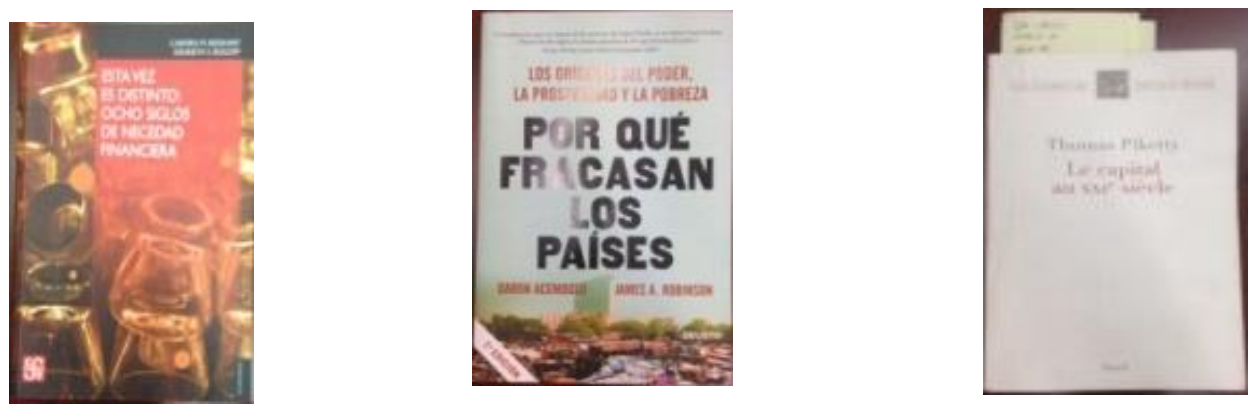

\footnotetext{
${ }^{7}$ Los libros de Reinhart y Rogoff( 2011) y de Acemoglu y Robinson (2012) fueron editados en inglés en el 2009 y 2012, respectivamente y el de Piketty (2013) ya está traducido al inglés desde el original francés, también en el 2013, y se espera que para el otoño/invierno de 2014 se publique la traducción española.
}

ISSN: 0212-8594 ISSN-e: 2340-2776.№ DOI: http://dx.doi.org/10.12795/rea.2015.i32.02

REA 32 (2015):22-48

http://editorial.us.es/es/revista-de-estudios-andaluces 
El libro de Reinhart y Rogoff, alineado con postulados liberales de economía de mercado: autores ambos con pasado en la Universidad de Harvard (USA) y en el Fondo Monetario Internacional; hoy trabajan respectivamente en las universidades de Maryland y en el Massachussets Institute of Tecnology (MIT). Acemoglu y Robinson, también del MIT y de la Universidad de Harvard, respectivamente; con una posición institucionalista del desarrollo económico y particularmente política. Y Piketty y su equipo de la EHESS y la Escuela de Economía de París, con una ideología cercana a una visión regulatoria e intervencionista en el desarrollo económico; si bien con formación previa en Boston.

Los tres best-sellers coinciden de manera asombrosa en cuatro cosas: 1.- La necesidad de hallar fuentes alternativas en la construcción estadística y reivindicar una mejora serial y correcta en las mismas, apropiada a los nuevos problemas de la Geografía Económica. La polémica sobre la idoneidad de la minería estadística está servida en los tres casos. 2.- La recuperación de las series históricas, a lo Braudel, particularmente desde la Revolución Industrial británica. Reconocer en números, gráficos y aparato formal, los comportamientos en la historia contemporánea de hechos económicos y países. 3.- Precisamente, el recurso a la regionalización del mundo y el tratamiento de diversos casos en la Geografía económica internacional (cómo se ha comportado en el tiempo hasta hoy, un país o una región mundial), es otro de los métodos elegidos: el estudio de casos significativos y comparables. 4.- El interés por la economía como ciencia social, por tanto con múltiples conexiones no exactas con la geografía, la política, la sociología etc., y la ayuda del aparato formal como simplificador de variables como medio y no como fin, de una explicación social de las cosas.

Las obras elegidas concitan coincidencias, procedencias y divergencias. Para tratar de resumir someramente el rico contenido de las tres y obtener una mirada comparativa y conjunta, hemos construidos Cinco Cuadros (del 1 al 5) que reflejan los Asuntos Centrales, los Temas específicos, los Enfoques Metodológicos y las Fuentes, el Desarrollo de Contenidos Fundamentales, y las Conclusiones y Recetas, finalmente, de los tres libros. 


\begin{tabular}{|c|c|c|c|c|}
\hline \multicolumn{5}{|c|}{ Cuadro 1. Best-Sellers en economía y geografía económica. } \\
\hline Libro & Título & & Asuntos centrales. & \\
\hline 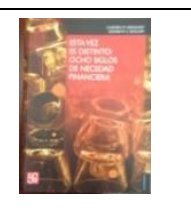 & $\begin{array}{l}\text { Esta vez es distinto } \\
\text { (Reinhart y Rogoff, } \\
\text { 2011) }\end{array}$ & $\begin{array}{l}\text { Crisis financieras en la historia } \\
\text { desde } 1800-2008 \text {. Diversas } \\
\text { regiones y países del mundo. }\end{array}$ & $\begin{array}{l}\text { Análisis del síndrome: "esta } \\
\text { vez es distinto": las crisis no } \\
\text { nos afectan aquí y ahora ("no } \\
\text { hay nada nuevo, salvo lo que } \\
\text { se ha olvidado") }\end{array}$ & $\begin{array}{l}\text { La naturaleza volátil de la } \\
\text { confianza, como el factor } \\
\text { clave de las debacles } \\
\text { financieras. }\end{array}$ \\
\hline 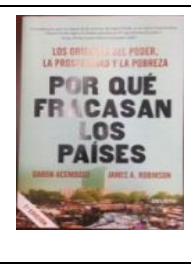 & $\begin{array}{l}\text { Por qué fracasan los } \\
\text { países (Acemoglu y } \\
\text { Robinson, 2012) }\end{array}$ & $\begin{array}{l}\text { El éxito económico de los } \\
\text { países difiere según las } \\
\text { instituciones y reglas de las } \\
\text { que se doten para su } \\
\text { funcionamiento político y } \\
\text { económico. }\end{array}$ & $\begin{array}{l}\text { Análisis de lo sucedido en las } \\
\text { instituciones políticas y } \\
\text { económicas en diversas } \\
\text { regiones y países del mundo } \\
\text { desde la Rev. Industrial } \\
\text { inglesa y la Rev. Francesa. }\end{array}$ & $\begin{array}{c}\text { Los países fracasan debido } \\
\text { a instituciones extractivas } \\
\text { y triunfan si se vertebran } \\
\text { en torno a instituciones } \\
\text { políticas y económicas } \\
\text { inclusivas. }\end{array}$ \\
\hline$F$ & $\begin{array}{l}\text { El capital en el siglo XXI } \\
\text { (Piketty, 2013) }\end{array}$ & $\begin{array}{l}\text { Dinámica de la distribución } \\
\text { territorial y social de rentas y } \\
\text { patrimonios desde el S.XVIII. }\end{array}$ & $\begin{array}{c}\text { La historia de la distribución } \\
\text { de la riqueza es política y no } \\
\text { se explica solo por } \\
\text { razonamientos económicos } \\
\text { (economía política) ni por } \\
\text { supuestos equilibrios } \\
\text { automáticos. }\end{array}$ & $\begin{array}{l}\text { En la distribución de la } \\
\text { riqueza y la desigualdad, } \\
\text { el capitalismo produce } \\
\text { mecanismos de } \\
\text { divergencia insostenibles } \\
\text { y arbitrarios. }\end{array}$ \\
\hline
\end{tabular}

ISSN: 0212-8594 ISSN-e: 2340-2776.№ DOI: http://dx.doi.org/10.12795/rea.2015.i32.02 


\begin{tabular}{|c|c|c|c|c|}
\hline \multicolumn{5}{|c|}{ Cuadro 2. Best-Sellers en economía y geografía económica. } \\
\hline Libro & Título & \multicolumn{3}{|c|}{ Temas específicos. } \\
\hline 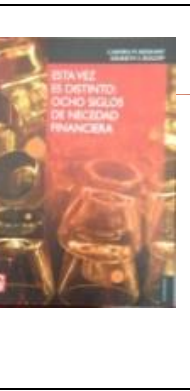 & $\begin{array}{l}\text { Esta vez es } \\
\text { distinto } \\
\text { (Reinhart y } \\
\text { Rogoff, 2011) }\end{array}$ & $\begin{array}{l}\text { Análisis del comportamiento de } \\
\text { las crisis financieras de tipo: } \\
\text { - inflacionarias } \\
\text { - bancarias } \\
\text { - monetarias } \\
\text { - "burbujas" } \\
\text { - deudas (publica/privada. } \\
\text { interna/externa). }\end{array}$ & $\begin{array}{l}\text { La crisis actual (2008) es un } \\
\text { parteaguas para la redefinición } \\
\text { de políticas. Afectará a una } \\
\text { generación. Las crisis globales } \\
\text { son más perniciosas porque } \\
\text { afectan a las exportaciones en su } \\
\text { conjunto. }\end{array}$ & $\begin{array}{l}\text { Las economías avanzadas } \\
\text { presentan entre (1800- } \\
\text { 2008) una serie sucesiva } \\
\text { de crisis bancarias. Las } \\
\text { burbujas son mucho más } \\
\text { perniciosas al nutrirse de } \\
\text { deuda. Relacióndirecta } \\
\text { entre crisis bancarias y } \\
\text { precios de la vivienda. }\end{array}$ \\
\hline $\begin{array}{l}\text { POR QUE } \\
\text { FR I CASAN } \\
\text { LOS } \\
\text { PAISES } \\
\text { PE }\end{array}$ & $\begin{array}{c}\text { Por qué } \\
\text { fracasan los } \\
\text { países } \\
\text { (Acemoglu y } \\
\text { Robinson,2012) }\end{array}$ & $\begin{array}{l}\text { Las instituciones económicas y } \\
\text { políticas inclusivas fomentan la } \\
\text { participación de las personas: } \\
\text {-seguridad propiedad privada } \\
\text {-sistema jurídico imparcial. } \\
\text {-servicios públicos para asegurar } \\
\text { la igualdad de oportunidades. } \\
\text {-fomento de la innovación } \\
\text { tecnológica y la movilización del } \\
\text { capital humano. } \\
\text {-instituciones pluralistas } \\
\text { (democracia) pero centralista del } \\
\text { poder de coacción. } \\
\text {-incentivos que motiven a las } \\
\text { personas, fomenten el } \\
\text { crecimiento y la redistribución. }\end{array}$ & $\begin{array}{l}\text { Las instituciones extractivas } \\
\text { (mayoritarias en el mundo) son } \\
\text { las que explotan los recursos de } \\
\text { toda la sociedad,para una élite } \\
\text { (grupos oligárquicos). } \\
\text {-tener destrucción creativa } \\
\text { (sustituye lo viejo por lo nuevo). } \\
\text { - jerarquía, orden, } \\
\text { desigualdades. } \\
\text { - periodos de crecimiento con } \\
\text { colapso. } \\
\text { - inestabilidad estructural. }\end{array}$ & $\begin{array}{l}\text { La dialéctica, por tanto, } \\
\text { se polariza entre países } \\
\text { con éxito, de tipo } \\
\text { inclusivo, y sociedades } \\
\text { fracasadas de corte } \\
\text { extractivo. }\end{array}$ \\
\hline 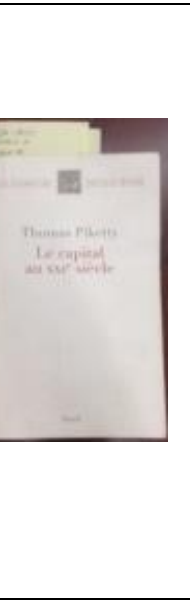 & $\begin{array}{l}\text { El capital en el } \\
\text { siglo XXI } \\
\text { (Piketty, 2013) }\end{array}$ & $\begin{array}{l}\text { La mayor tendencia histórica hacia } \\
\text { la convergencia son los procesos } \\
\text { de difusión del conocimiento y la } \\
\text { inversión en habilidades y } \\
\text { formación de la fuerza de trabajo } \\
\text { y capital humano. }\end{array}$ & $\begin{array}{c}\text { La ecuación clave es: } \\
r>\mathrm{g} \\
\text { (tasa de rendimiento capital 4\%- } \\
5 \% \text { ) } \\
\text { (Tasa de crecimiento de } \\
\text { producción y salarios } 1 \%-1,5 \% \text { ) } \\
\text { esta contradicción del } \\
\text { capitalismo hace que los } \\
\text { patrimonios hereditarios } \\
\text { dominen y se retroalimenten } \\
\text { con más velocidad que las } \\
\text { inercias meritocráticas. El } \\
\text { empresario inevitablemente se } \\
\text { convierte en rentista. }\end{array}$ & $\begin{array}{l}\text { El reparto mundial de la } \\
\text { riqueza ha entrado en } \\
\text { una fase convergente } \\
\text { desde 1980: de bloques } \\
\text { mundiales a regionales. } \\
\text { (Media } 600 \text { euros mes, de } \\
\text { 110-3000 de país de } \\
\text { menor a mayor renta } \\
\text { mensual). }\end{array}$ \\
\hline & & & \multicolumn{2}{|c|}{\begin{tabular}{|l|l} 
& Fuente: Elaboración propia.
\end{tabular}} \\
\hline
\end{tabular}

ISSN: 0212-8594 ISSN-e: 2340-2776.N№ DOI: http://dx.doi.org/10.12795/rea.2015.i32.02 


\begin{tabular}{|c|c|c|c|c|c|}
\hline \multicolumn{6}{|c|}{ Cuadro 3. Best-Sellers en economía y geografía económica. } \\
\hline Libro & Título & \multicolumn{4}{|c|}{ Enfoque metodológico y fuentes } \\
\hline 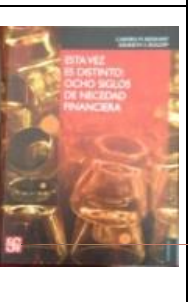 & $\begin{array}{l}\text { Esta vez es } \\
\text { distinto } \\
\text { (Reinhart y } \\
\text { Rogoff, 2011) }\end{array}$ & $\begin{array}{c}\text { Insuficiencia de } \\
\text { información: ausencia } \\
\text { de indicadores } \\
\text { acertados para detectar } \\
\text { las crisis. }\end{array}$ & $\begin{array}{l}\text { Opacidad práctica de } \\
\text { los estados, en su } \\
\text { estadística de deuda, } \\
\text { sobre todo de la interna } \\
\text { (2/3 parte, de la deuda } \\
\text { pública mundial) }\end{array}$ & $\begin{array}{l}\text { Necesidad de } \\
\text { coordinación política y } \\
\text { estadística en términos } \\
\text { de la regulación } \\
\text { financiera, y de la } \\
\text { movilidad del capital } \\
\text { internacional. }\end{array}$ & $\begin{array}{l}\text { Fuentes y series } \\
\text { estadísticas } \\
\text { controvertidas. }\end{array}$ \\
\hline 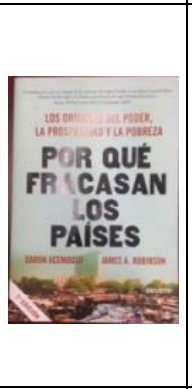 & $\begin{array}{l}\text { Por qué fracasan } \\
\text { los países } \\
\text { (Acemoglu y } \\
\text { Robinson, 2012) }\end{array}$ & $\begin{array}{l}\text { Interpretación de lo } \\
\text { sucedido en países } \\
\text { desde el XVIII (y antes } \\
\text { según casos) hasta hoy: } \\
\text { reivindicación de las } \\
\text { ciencias sociales } \\
\text { (historia y sociología). }\end{array}$ & $\begin{array}{c}\text { Ni la geografía (física), } \\
\text { ni la cultura } \\
\text { (modernización), ni la } \\
\text { ignorancia en política } \\
\text { económica (la } \\
\text { prosperidad no se } \\
\text { puede diseñar) ayudan } \\
\text { a explicar el fracaso de } \\
\text { los países. } \\
\end{array}$ & $\begin{array}{l}\text { El análisis de casos } \\
\text { (países) es el método } \\
\text { elegido. El devenir } \\
\text { circunstancial de la } \\
\text { historia: el desarrollo } \\
\text { institucional es } \\
\text { contingente. }\end{array}$ & $\begin{array}{l}\text { Práctica ausencia de } \\
\text { aparato formal } \\
\text { económico. }\end{array}$ \\
\hline$\sum^{2}$ & $\begin{array}{c}\text { El capital en el } \\
\text { siglo XXI (Piketty, } \\
\text { 2013) }\end{array}$ & $\begin{array}{l}\text { Debilidad de la } \\
\text { información } \\
\text { convencional para } \\
\text { explorar en la temática } \\
\text { de las desigualdades y } \\
\text { comportamiento del } \\
\text { capital (se acude a la } \\
\text { literatura y al } \\
\text { periodismo). }\end{array}$ & $\begin{array}{c}\text { Se usan métodos } \\
\text { empíricos a base de } \\
\text { experimentación } \\
\text { controlada: } \\
\text { causalidades históricas. }\end{array}$ & $\begin{array}{l}\text { La investigación en } \\
\text { ciencias sociales no tiene } \\
\text { vocación de producir } \\
\text { certidumbres } \\
\text { matemáticas y si } \\
\text { sustituir al debate } \\
\text { público, democrático y } \\
\text { contradictorio. }\end{array}$ & $\begin{array}{l}\text { Fuentes y series } \\
\text { estadísticas } \\
\text { controvertidas. }\end{array}$ \\
\hline
\end{tabular}

ISSN: 0212-8594 ISSN-e: 2340-2776.№ DOI: http://dx.doi.org/10.12795/rea.2015.i32.02 


\begin{tabular}{|c|c|c|c|c|c|c|}
\hline \multicolumn{7}{|c|}{ Cuadro 4. Best-Sellers en economía y geografía económica. } \\
\hline Libro & Título & \multicolumn{5}{|c|}{ Desarrollo de contenidos fundamentales } \\
\hline 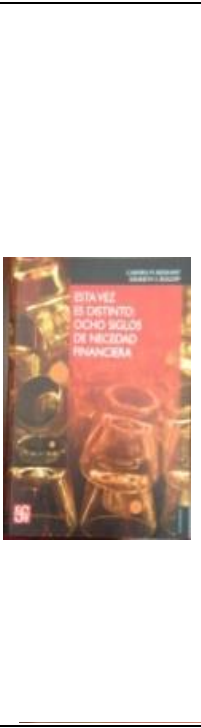 & $\begin{array}{l}\text { Esta vez es } \\
\text { distinto } \\
\text { (Reinhart y } \\
\text { Rogoff, } \\
\text { 2011) }\end{array}$ & $\begin{array}{c}\text { No existe inmunidad } \\
\text { a las crisis. Fuerte } \\
\text { intolerancia a la } \\
\text { deuda y } \\
\text { vulnerabilidad en los } \\
\text { países emergentes. } \\
\text { Importancia de la } \\
\text { corrupción y la } \\
\text { gobernabilidad. }\end{array}$ & $\begin{array}{c}\text { El } \\
\text { perfeccionamien } \\
\text { to de las } \\
\text { instituciones y } \\
\text { políticas no } \\
\text { salvaguardan de } \\
\text { que } \\
\text { históricamente } \\
\text { se sobrepase los } \\
\text { límites (codicia, } \\
\text { intereses, lucros) }\end{array}$ & $\begin{array}{l}\text { Los periodos de } \\
\text { endeudamiento } \\
\text { fuerte, aun largos, } \\
\text { convergen en crisis } \\
\text { prácticamente } \\
\text { seguras. }\end{array}$ & $\begin{array}{l}\text { Los países no } \\
\text { morosos } \\
\text { poseen } \\
\text { historias de } \\
\text { crecimiento } \\
\text { exitosas. Los } \\
\text { estados } \\
\text { pagan más } \\
\text { por su } \\
\text { voluntad que } \\
\text { por } \\
\text { capacidad de } \\
\text { hacerlo. }\end{array}$ & $\begin{array}{c}\text { Las crisis } \\
\text { bancarias } \\
\text { en } \\
\text { economías } \\
\text { avanzadas } \\
\text { deprimen el } \\
\text { crecimiento } \\
\text { mundial. El } \\
\text { descenso } \\
\text { del precio } \\
\text { de las } \\
\text { materias } \\
\text { primas } \\
\text { reduce la } \\
\text { capacidad } \\
\text { del pago de } \\
\text { la deuda. }\end{array}$ \\
\hline 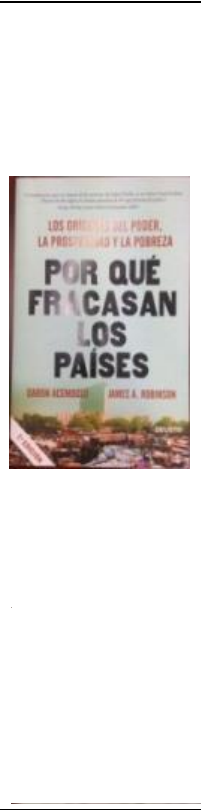 & $\begin{array}{c}\text { Por qué } \\
\text { fracasan } \\
\text { los países } \\
\text { (Acemoglu } \\
\text { y } \\
\text { Robinson, } \\
\text { 2012) }\end{array}$ & $\begin{array}{c}\text { En países con } \\
\text { instituciones } \\
\text { extractivas, las élites } \\
\text { asignan recursos a } \\
\text { actividades de alta } \\
\text { productividad que } \\
\text { controlan } \\
\text { directamente. No se } \\
\text { origina desarrollo } \\
\text { sostenido ni } \\
\text { destrucción } \\
\text { creativa.Concentraci } \\
\text { ón de riqueza y Ley } \\
\text { de Hierro de la } \\
\text { oligarquía. Codicia } \\
\text { por el poder } \\
\text { económico } \\
\text { extractivo (círculo } \\
\text { vicioso). }\end{array}$ & $\begin{array}{l}\text { Vínculos entre el } \\
\text { pluralismo } \\
\text { político (reparto } \\
\text { poder político) y } \\
\text { la centralización } \\
\text { (monopolio del } \\
\text { Estado de la ley y } \\
\text { el orden) para la } \\
\text { inclusión exitosa. } \\
\text { El hecho de que } \\
\text { exista } \\
\text { democracia } \\
\text { formal no } \\
\text { asegura el } \\
\text { pluralismo. }\end{array}$ & $\begin{array}{l}\text { Las desigualdades } \\
\text { institucionales son } \\
\text { la clave para } \\
\text { comprender como } \\
\text { apareció la } \\
\text { desigualdad } \\
\text { económica } \\
\text { mundial, desde la } \\
\text { Rev. Industrial } \\
\text { británica. }\end{array}$ & \multicolumn{2}{|c|}{$\begin{array}{l}\text { El desarrollo inclusivo } \\
\text { provoca círculos virtuosos } \\
\text { de crecimiento económico } \\
\text { por los equilibrios de poder } \\
\text { que se originan entre los } \\
\text { distintos sectores sociales y } \\
\text { económicos. }\end{array}$} \\
\hline Lxwerte & $\begin{array}{c}\text { El capital } \\
\text { en el siglo } \\
\text { XXI } \\
\text { (Piketty, } \\
\text { 2013) }\end{array}$ & $\begin{array}{c}\text { Los países que se } \\
\text { sitúan en la frontera } \\
\text { tecnológica no } \\
\text { pueden crecer a } \\
\text { ritmo chino o de } \\
\text { entreguerras (ley del } \\
\text { crecimiento } \\
\text { acumulado). Fin del } \\
\text { crecimiento con } \\
\text { altas tasas, con una } \\
\text { tasa } 1 \% \text { la sociedad } \\
\text { se renueva } \\
\text { profundamente. } \\
\end{array}$ & $\begin{array}{l}\text { La inserción } \\
\text { internacional no } \\
\text { tiene nada de } \\
\text { negativo en sí. } \\
\text { Las autarquías } \\
\text { no son } \\
\text { prosperas. }\end{array}$ & $\begin{array}{l}\text { La relaciónentre la } \\
\text { tasa de } \\
\text { rendimiento del } \\
\text { capital y la tasa de } \\
\text { crecimiento de la } \\
\text { producción y los } \\
\text { salarios tiene } \\
\text { efectos } \\
\text { extremadamente } \\
\text { poderosos y } \\
\text { desestabilizadores } \\
\text { en las } \\
\text { desigualdades. } \\
\end{array}$ & \multicolumn{2}{|c|}{$\begin{array}{l}\text { Las desigualdades en los } \\
\text { países emergentes son } \\
\text { menores que en USA } \\
\text { (superingresos de los altos } \\
\text { ejecutivos) }\end{array}$} \\
\hline & & & & & Fuente: Elab & ción propia. \\
\hline
\end{tabular}

ISSN: 0212-8594 ISSN-e: 2340-2776.N№ DOI: http://dx.doi.org/10.12795/rea.2015.i32.02

REA 32 (2015):22-48

http://editorial.us.es/es/revista-de-estudios-andaluces 


\begin{tabular}{|c|c|c|c|c|c|c|}
\hline \multicolumn{7}{|c|}{ Cuadro 5. Best-Sellers en economía y geografía económica. } \\
\hline Libro & Título & \multicolumn{5}{|c|}{ Conclusiones y recetas } \\
\hline 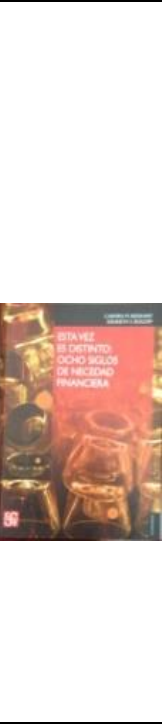 & $\begin{array}{c}\text { Esta vez es } \\
\text { distinto } \\
\text { (Reinhart } \\
\text { y Rogoff, } \\
\text { 2011) }\end{array}$ & \begin{tabular}{|c|} 
La alta movilidad del \\
capital internacional \\
tiene una correlación \\
directa con las crisis \\
bancarias: \\
- se duplicala deuda \\
pública. \\
-fuertes caídas de empleo \\
y producción. \\
-se colapsa mercado de \\
activos (mejor \\
comportamiento de \\
acciones que de \\
viviendas). \\
-disminuyen los ingresos \\
fiscales por la contracción \\
del crecimiento. \\
\end{tabular} & $\begin{array}{l}\text { La deuda } \\
\text { soberana se } \\
\text { soluciona } \\
\text { históricamente } \\
\text { con: } \\
\text {-inflación. } \\
\text {-emisión } \\
\text { moneda. } \\
\text {-incumplimiento } \\
\text { deuda externa. }\end{array}$ & $\begin{array}{l}\text { Necesidad } \\
\text { urgente de un } \\
\text { organismo } \\
\text { supervisor } \\
\text { internacional, } \\
\text { regulador de la } \\
\text { movilidad del } \\
\text { capital. }\end{array}$ & & \\
\hline 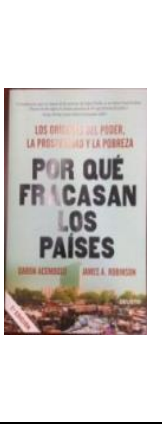 & $\begin{array}{c}\text { Por qué } \\
\text { fracasan } \\
\text { los países } \\
\text { (Acemoglu } \\
y \\
\text { Robinson, } \\
2012 \text { ) }\end{array}$ & \begin{tabular}{|c|} 
Los países fracasan por \\
instituciones extractivas y \\
su retroalimentada \\
persistencia. Abusos de \\
poder, Estado fracasado, \\
ausencia de ley, \\
aplastamiento de la \\
prosperidad económica y \\
sus incentivos en ahorro, \\
inversión e innovación.
\end{tabular} & $\begin{array}{l}\text { La clave del éxito } \\
\text { de los países es } \\
\text { remover las } \\
\text { instituciones } \\
\text { extractivas en } \\
\text { inclusivas } \\
\text { rompiendo } \\
\text { círculos viciosos. }\end{array}$ & $\begin{array}{l}\text { El conflicto por } \\
\text { la renta y el } \\
\text { poder e } \\
\text { indirectamente } \\
\text { por las } \\
\text { instituciones } \\
\text { políticas, es } \\
\text { una constante } \\
\text { histórica. }\end{array}$ & $\begin{array}{l}\text { La articulación entre } \\
\text { prosperidad e } \\
\text { instituciones políticas } \\
\text { y económicas } \\
\text { inclusivas: cambio } \\
\text { institucional } \\
\text { (coyunturas críticas). }\end{array}$ & $\begin{array}{c}\text { la gran } \\
\text { interrogante } \\
\text { china: el } \\
\text { irresistible } \\
\text { encanto del } \\
\text { crecimiento } \\
\text { autoritario }\end{array}$ \\
\hline$=7$ & $\begin{array}{c}\text { El capital } \\
\text { en el siglo } \\
\text { XXI } \\
\text { (Piketty, } \\
\text { 2013) }\end{array}$ & $\begin{array}{c}\text { Desde } 1980 \text { los } \\
\text { patrimonios han } \\
\text { progresado más } \\
\text { rápidamente que los } \\
\text { ingresos: } 1 \% \text { de los más } \\
\text { ricos }=50 \% \text { patrimonio } \\
\text { mundial. }\end{array}$ & $\begin{array}{l}\text { Las divergencias } \\
\text { de la } \\
\text { acumulación } \\
\text { oligárquica son } \\
\text { más peligrosas } \\
\text { que las } \\
\text { divergencias } \\
\text { entre países. La } \\
\text { dimensión } \\
\text { patrimonial de } \\
\text { los países ricos, } \\
\text { es mucho mayor } \\
\text { que la aparente } \\
\text { (paraísos } \\
\text { fiscales, capital } \\
\text { inmobiliario). } \\
\end{array}$ & $\begin{array}{l}\text { Receta: regular } \\
\text { el capital en el } \\
\text { siglo XXI. } \\
\text { Retorno al } \\
\text { Estado Social. } \\
\text { Crisis 2008: } \\
\text { crisis del } \\
\text { capitalismo } \\
\text { patrimonial. }\end{array}$ & \begin{tabular}{|} 
Un impuesto mundial \\
y anual sobre el \\
capital. Una utopía: 5- \\
$10 \%$ para las grandes \\
fortunas (control de \\
las transmisiones \\
automáticas \\
bancarias. \\
Redistribución renta \\
petrolera. Los \\
impuestos progresivos \\
como motor \\
redistribuidor)
\end{tabular} & \\
\hline & & & & & Fuente: Elaboraci & propia. \\
\hline
\end{tabular}

ISSN: 0212-8594 ISSN-e: 2340-2776.N№ DOI: http://dx.doi.org/10.12795/rea.2015.i32.02 
De la lectura de estas Imágenes o Cuadros/Resumen, podríamos extraer algunas conclusiones generales, que podrían ponderar los elementos nucleares de la preocupación económica más difundida después de la crisis del 2008. Siempre, en cuanto afecte a la Geografía Económica de escala global:

1.- En primer lugar, los temas centrales que atacan los autores son las Crisis Financieras, el éxito o fracaso de los países y el comportamiento del capital. En todos los casos, se utiliza el período que viene desde la Revolución Industrial inglesa, como el parteaguas que marca el camino en la medición de las desigualdades mundiales. Estos tres temas tienen un común denominador: reconocer según cada interpretación cuáles son los elementos centrales de la economía política en este período (la historia económica contemporánea), y a su vez como estos tres temas centrales configuran un mapa mundial de la Geografía Económica muy parecido. Donde se deviene de la categoría tradicional de Norte/Sur a parámetros de distribución de la riqueza y la desigualdad, y del fracaso de los países en su viabilidad económica y política (prosperidad), a asuntos más sutiles de reiteración en las crisis financieras (ya en países ricos o emergentes), de la importancia del carácter de las instituciones y de la mayor divergencia entre los deciles más altos de concentración de la riqueza entre propietarios del capital, que entre países.

Una cuestión se reitera, queda abandonado el paradigma "dependentista" de la explotación de los países ricos por los pobres, y se entra de lleno en las responsabilidades internas (que pueden explicarse históricamente por procesos de colonización política o económica) de las élites locales en la gestión de las crisis financieras, el fracaso de los países o las concentraciones patrimoniales del capital. Eso sí, es la internacionalización del capital y de sus flujos a través de transacciones bancarias, paraísos fiscales y acaparamiento inmobiliario y de activos en general (patrimonios encubiertos, fondos de inversión, banca de inversión) el gran asunto del Siglo XXI, en la geografía económica internacional.

2.- Según cada obra encontraremos, respectivos "leitmotiv", en el caso de la crisis financieras, la nociva creencia-incentivada por la desmedida ambición y lucro- del "esta vez es distinto"; sobre el fracaso de los países, la causalidad extractiva y no inclusiva en la articulación de su sociedad y economía ;y para explicarnos cómo se comporta el capital del Siglo XXI, se insiste en que la tasa acumulada del rendimiento

\footnotetext{
${ }^{8}$ Desde luego, el éxito exportador de los países emergentes en sectores industriales, no sólo de industria ligera y de bajo aporte tecnológico y, por supuesto, en sectores extractivos, ha ocasionado un efecto directo de deslocalización y desmantelamiento de las industrias denominadas antes básicas y también de ciertos bienes de consumo, de los países centrales. El círculo vicioso del intercambio desigual, de la Teoría Centro Periferia incubada en CEPAL por Prebisch, Furtado, Cardoso, Faletto y otros, roto en buena medida por la globalización. Una visión Cepalina más descafeinada por las influencias neoliberales en los noventa del siglo XX, es el paradigma deL Crecimiento con Equidad (Cepal, 1990).
}

ISSN: 0212-8594 ISSN-e: 2340-2776.N№ DOI: http://dx.doi.org/10.12795/rea.2015.i32.02

REA 32 (2015):22-48

http://editorial.us.es/es/revista-de-estudios-andaluces 
del capital es siempre mayor que la tasa de crecimiento de la producción y los salarios. En fin, la inevitable conversión de emprendedores a rentistas, de la sustitución de la meritocracia por la herencia del patrimonio, como "leitmotiv" en la geografía económica internacional.

Secuencias de crisis financieras, élites y gobiernos extractivos y rendimientos del capital patrimonial, son las claves explicativas de las profundas desigualdades mundiales entre países y clases -es absurdo para Piketty que se haya sustituido la lucha de clases, por la lucha de edades (confrontación generacional por las rentas)- y de las divergencias que el capitalismo como estructura económica genera retroalimentariamente. Esto último es sólo reconocido explícitamente por Piketty, y de manera implícita y de forma tibia por el resto. De lo que no hay duda es del rotundo fracaso en todos los órdenes, pese al episodio de crecimiento estalinista, del comunismo soviético (un enfoque castrista puede encontrarse en Celis, 1988).

3.- Existe una absoluta y asombrosa coincidencia: el rol incontrolado y perverso para la equidad, de los flujos de capital internacional ${ }^{9}$. Es preciso, supervisarlos con organismos internacionales "ad hoc" y con más eficiencia en su gestión, según Reinhart y Rogoff. Deben ser mecanismos institucionales -multilaterales y en los propios países- inclusivos para incentivar la prosperidad, para Acemoglu y Robinson. Desde luego para Piketty, la única solución es la regulación del capital internacional a través de la fiscalidad progresiva. Así es, aunque lo considera una utopía en el actual estado de cosas, no cabe otra para retornar al Estado Social, ante este capitalismo "fou" que modernizar las estructuras públicas, sobre la base de la redistribución impositiva. Los impuestos progresivos sobre el capital, según el autor francés, son una manera infinitamente preferible, en términos de justicia y eficacia, que la deuda para la modernización del Estado Social. Asunto central hoy, que suele solucionarse también en los países emergentes con inflación pagada por todos (rol monopólico del Estado: sobreemisiones de moneda) o por la austeridad y recortes, a la manera alemana y de la Eurozona ${ }^{10}$.

\footnotetext{
9 Es sintomático que el Premio Nobel de Economía de 2014, haya sido concedido a Jean Tirole (precisamente un francés -influido por la teoría de la regulación de M. Boyer-de la Universidad de Toulouse), por sus aportaciones a los denominados fallos del mercado. A sus planteamientos sobre el poder de los mercados y su regulación: "Sin un regulador fuerte, no hay liberalización eficaz", declaraba en El País, ya en junio de 2005.

${ }^{10}$ Desde luego que es el asunto central del debate social y político de hoy en sociedades como la española. Rainhart y Rogoff en un tono neoclásico, acuden a la explicación de que los países como España pueden pagar más de lo que quieren. Se trata de un problema político de voluntad, no de la relación entre liquidez y deuda. En todo caso, para eso están los ajustes y recortes. Los Estados están más cómodos acudiendo a la deuda que a la imposición progresiva. Sin embargo, como dice Piketty, el problema del pago de la deuda soberana es que engrosa los patrimonios de los capitalistas internacionales $-\mathrm{y}$ no se olvide a los nacionales con deuda interna- que a través de fondos de renta fija o de derivados en variable, invierten en ella. Es decir, los recortes o la imposición fiscal menos progresiva con el aumento explosivo de la deuda pública -ecuación clásica según Rainhart y Rogoff de una crisis financiera- coadyuvan a una extracción creciente de recursos públicos hacia multimillonarios,
} 
La Utopía a lo Piketty, consistiría en un impuesto mundial anual sobre el capital controlado a través de las transmisiones automáticas de las cuentas bancarias (ello sería una auténtica revolución para el secreto bancario y los paraísos fiscales tanto los reconocidos como los no reconocidos, tipo Luxemburgo). Tal Utopía comportaría una auténtica cooperación política y la integración regional de la Geografía Económica Internacional. Afectaría, por ejemplo, no sólo a la opacidad de las transmisiones e inversiones de los grandes capitales mundiales sino también a la redistribución de la renta petrolera. Piketty, propone desde el 0,1\%-0,5\% para capitales de menos de un millón de euros, el 2\% para tramos entre 5-10 millones de euros, hasta entre el 5\%$10 \%$ para fortunas de millardos de euros.

4.- Otro asunto en el que hay natural coincidencia es que la tecnología al igual que el mercado, no conoce ni límites, ni moral. El crecimiento moderno, fundamentado en el aumento constante de la productividad de los conocimientos e innovaciones, sin embargo, no ha modificado las estructuras profundas del capital (de hondo contenido patrimonialista). Ello, siguiendo a Acemoglu y Robinson, se agudiza en modelos extractivos; suscitándose de forma casi inevitable, la confrontación por la apropiación de dichas rentas extractivas de grupos oligarcas versus grupos oligarcas. La centralidad del Estado se fractura, el pluralismo inclusivo desaparece por la codicia por un poder político al cual se asalta y perpetúa normalmente por la fuerza, aunque en el país exista democracia formal (caso ruso).

Por la hondura de la crisis del 2008, para todos los autores: la primera crisis del capitalismo patrimonial mundial (derrumbe del valor de los activos), y las contracciones en el crecimiento, el asunto medioambiental es prácticamente una variable secundaria. Es asumido por todos, el componente de los costes ambientales, se reconoce el calentamiento atmosférico y el cambio climático, se vuelve a repasar a Malthus, pero en las tres obras, es el problema del crecimiento y sus obstáculos nucleares para una prosperidad sostenida -mejor que sostenible-, a saber, las crisis financieras, las instituciones extractivas y el rentismo del capital, las variables centrales. El capital natural no cuenta ni cómo envolvente clave en el futuro y sostenibilidad del planeta; ni cómo magnitud nuclear en las cuentas económicas. Al menos cabría un recordatorio que luego de los años ochenta del Siglo XX, se instaura en el discurso económico, el tópico de desarrollo sostenible ${ }^{11}$. Nos remitimos a la escasa repercusión y fracaso de la Cumbre Ambiental de Nueva York de los últimos días de septiembre del 2014.

acrecentando la desigualdad. Tarea política sería identificar a los mercados, con nombres y apellidos no societarios, si no de personas físicas.

${ }^{11}$ En Septiembre del 2014, El club de las grandes empresas siderúrgicas europeas ha enviado una carta abierta a la Comisión, donde literalmente plantea que en la globalización y la competencia con los países emergentes, la dialéctica competitividad vs cambio climático para su sector, sólo puede decantarse por la competitividad y desregulación ambiental, si no se quiere desmantelar y deslocalizar dicha industria de la Unión Europea. Asunto recogido por Financial Times.

ISSN: 0212-8594 ISSN-e: 2340-2776.N№ DOI: http://dx.doi.org/10.12795/rea.2015.i32.02

REA 32 (2015):22-48

http://editorial.us.es/es/revista-de-estudios-andaluces 
5.- Sobre el enfoque geográfico, se refuerza la taxonomía clásica entre países ricos y pobres desde la revolución industrial británica y el liderazgo de USA en el siglo XX, la creación de la Unión Europea, la recesión crónica japonesa y los países nuevos anglosajones como también espacios centrales de la Geografía Económica mundial. Sin embargo, el estudio de casos deriva en los libros analizados a concepciones de integración regional por encima de países y, particularmente, a la consideración de los denominados países emergentes: alto crecimiento poco inclusivo, por tanto crecimiento sin destrucción creativa abocado al colapso. Nueva versión de la dialéctica tradicional entre crecimiento/desarrollo.

Pero nos parece más subrayable, el asunto de, dado el crecimiento extractivo de los países emergentes y el envejecimiento demográfico de los bloques centrales, las divergencias internacionales en general tienden a aminorarse, aunque sea aparentemente. El verdadero círculo vicioso de la desigualdad estriba en la acumulación progresiva de capital por parte de los multimillonarios, que aunque con residencias formales en países, no es tan transparente su domicilio fiscal (paraísos fiscales) y su patriotismo económico (derivados y fondos de inversión). Dicho de otra forma, la divergencia oligárquica, crece más rápidamente que la divergencia entre países. Muestra de ello es USA y ahora China y Rusia. La concentración del capital entre los multimillonarios comporta, según los cálculos de Piketty, que el $1 \%$ de los más ricos (45 millones de adultos) posee el $50 \%$ del patrimonio mundial.

6.- Sobre las fuentes y los métodos de las investigaciones reseñados, aparte del carácter monumental de las tres obras por su metraje y recorrido temporal y espacial siempre con la Revolución Industrial como inicio de las grandes desigualdades y divergencias, siempre con la Crisis del 1929, como referencia ineludible en relación a la crisis actual- tienen comunes denominadores. Destacaríamos sobre todo como enganche con la Nueva Geografía Económica, no tanto la obsesión por el aparato formal en sí mismo, como la búsqueda de fuentes y datos que pudieran a través de modelos, gráficos y series contestar a las preguntas claves, de las crisis financieras, el fracaso de los países y el comportamiento del capital en un mundo de bajo crecimiento. Ello tiene además en el análisis de casos (países o regiones mundiales) una acertada correspondencia.

Por tratar de responder a preguntas nuevas(o viejas, mejor, pero con enfoque nuevo) y complejas, donde el aparato estadístico es inexistente, opaco o insuficiente (las series de Madison sobre variables internacionales están referidas en las tres obras) se utilizan todo tipo de fuentes indirectas. Por ejemplo Forbes o la novela narrativa del siglo XIX, o las donaciones de multimillonarios a las universidades de élite norteamericanas. Y se construyen nuevos indicadores o explicaciones, con el objeto de resolver las hipótesis observadas, como el problema de la confianza en las crisis financieras o el de la devolución de la deuda en Reinhart y Rogoff; la utilización de la historia política y del devenir contingente y circunstancial de los hechos históricos en Acemoglu y Robinson; - los métodos empíricos sobre series históricas de activos de capital, precios, 
demográficas etc., buscando las causalidades y tendencias en los gráficos confeccionados, como hace Piketty.

Todo ello podemos orientarlo, en la lectura atenta de estos "bestsellers" al menos hacia dos hechos convergentes, en primer lugar, la recuperación de la importancia de las ciencias sociales en general, por la imposibilidad de resolver problemas de alta complejidad sólo con una lógica económica y menos con la mera modelización formal. Por lo mismo, y segundo, se ha provocado un debate fuerte y numerosas críticas por parte de autores más ortodoxos en su concepción formal económica, a Piketty y a Acemoglu y Robinson, y a Reinhart y Rogoff, a la inversa, por los más postkeynesianos. En cualquier caso, se ponen en duda, la veracidad científica de los análisis construidos $^{12}$, dadas las fuentes y datos posibles y los indicadores construidos y su explicación.

Pero, en fin, la polémica suscitada nos conduce a concluir con todos los autores analizados, que la investigación en ciencias sociales y por ende, en la Geografía Económica, no tiene una vocación de producir certidumbres matemáticas y así sustituir al debate público, democrático y contradictorio. En el caso de Acemoglu y Robinson, en su afán de explicación institucionalista de las cosas, se concluye por ejemplo en una dicotomía medio radical -casi simplista- pero pedagógica y atractiva, entre sociedades extractivas abocadas al fracaso e inclusivas de desarrollo próspero y sostenible. Es en la práctica, una interpretación basada en el método histórico y sociológico; muy alejada de las ecuaciones economicistas.

\section{CONCLUSIONES: DERIVADAS EN EL PAISAJE, EL MEDIO Y LA ORDENACIÓN DE TERRITORIO.}

Pudiera parecer forzado terminar este trabajo con las reflexiones que promete el título del epígrafe, por acomodarlas precisamente al título del artículo propuesto. En parte lo es, por el uso de la escala global que contienen los análisis de los" best-sellers" empleados y porque como se demuestra por las páginas anteriores, nos ha interesado más el interés por una denominada Nueva Geografía Económica. Sin embargo, hay ciertos elementos en estos superventas que nos parecería conveniente destacar. El primero de todos, es el de la observación tajante -sobre todo en Acemoglu y Robinson- de que el determinismo geográfico, entendida la Geografía, como Geografía Física y del Clima, no ayudan a explicar ni la distribución de las crisis, ni el éxito de los países, ni el comportamiento del capital. Como tampoco el determinismo cultural o religioso -mentalidad económica católica vs luterana: los procesos de modernización social weberianos, no aciertan a entender los países nuevos o emergentes; o la

\footnotetext{
${ }^{12}$ Particularmente fuerte la polémica de Reinhart y Rogoff con Krugman al respecto. O las referencias de Piketty, precisamente, sobre Acemoglu y Robinson, a cuenta de Carlos Slim y Bill Gates. En cualquier caso, puede seguirse en las páginas webb de los autores o en el New York Times, en los meses siguientes a la publicación de sus respectivas obras. Piketty y Reinhart y Rogoff, descubren su arsenal y minería estadística en formato digital complementario al libro escrito.
}

ISSN: 0212-8594 ISSN-e: 2340-2776.N№ DOI: http://dx.doi.org/10.12795/rea.2015.i32.02

REA 32 (2015):22-48

http://editorial.us.es/es/revista-de-estudios-andaluces 
ignorancia en política económica, solucionada con diseños salvadores de tecnócratas extranjeros para países con crisis estructurales, tipo FMI. La prosperidad no se puede diseñar, dicen Acemoglu y Robinson.

La explicación sobre las desigualdades en la Geografía Económica a escala global, tiene como ya hemos visto según el correlato de los autores elegidos, componentes sobre todo de carácter institucional y político que deben ser estudiados por el comportamiento de sociedades, países y regiones mundiales a través de la causalidad histórica, por lo menos desde finales del Siglo XVIII. A fuer de ser repetido, son las construcciones de series estadísticas históricas sobre las causas de la desigualdad territorial y social en el mundo, junto al estudio de casos, el común denominador de lo analizado más arriba. Dicho esto qué cosas - de manera muy sintética y eligiendo la fundamental- podríamos relacionar con conceptos generales sobre el medio y las actividades económicas: paisaje, medio y ordenación del territorio?

Sobre Paisaje, nunca aparece en los textos como expreso concepto geográfico; en realidad no lo hace en el sentido lato del término. En todo caso, tiene un valor de forma de la ciudad y el campo, después de una guerra, una crisis, un desarrollo urbano explosivo, como plástica de las actividades agrarias etc. Un valor más que residual. En la mirada de los "best-sellers" consultados, el paisaje es un mero elemento estético producto de las acciones del mercado, las contingencias históricas y la modelación de las crisis económicas sobre el territorio. Particularmente en lo que afecta al desarrollo urbano en las sociedades extractivas/inclusivas y en las consecuencias del exutorio migratorio en el paisaje rural. El Paisaje no aparece como variable en la Geografía Económica de los textos consultados. Era de esperar, si no es como expresión territorial de los acontecimientos históricos y económicos, o puramente como elemento subsidiario estético/contemplativo.

Sobre Medio, ya lo hemos insinuado antes, es notoria la escasa preocupación por la problemática medioambiental. Acontece que en las situaciones de Crisis Global como la que sufrimos desde 2008, donde se tratan de desentrañar continuidades históricas o lecciones de las anteriores (sobre todo el crack del 29), donde además se concede una trascendente importancia a las instituciones políticas y al capital internacional, cada día más intangible en sus flujos, en unos inicios del siglo XXI, donde no se acierta a reactivar el crecimiento de las economías centrales, el Medio se difumina o desaparece. En ninguno de los textos es una variable central en el análisis, participa como hecho consumado el cambio climático pero que la tecnología reparará o las situaciones límites tenderán a recomponerse en su momento -no tenemos un problema hasta que no lo tengamos en la frente-. Se asume implícitamente el calentamiento del planeta, pero sigue siendo variable exógena en los razonamientos sobre crisis financiera, fracaso de los países -la Geografía física no explica la prosperidad o el subdesarrollo, según los autores- o estructura del capital. El Medio es un problema para el crecimiento, pero tendrá solución tecnológica. Ni las Cumbres sobre el Planeta como la de Kyoto, tienen mayor sitio; solo el canje de deuda por

ISSN: 0212-8594 ISSN-e: 2340-2776.№ DOI: http://dx.doi.org/10.12795/rea.2015.i32.02 
bonos de emisión de CO2, aparece como dato en Reinhart y Rogoff. En todo caso, paisaje y medio siguen siendo explicados en estos superventas como soportes de la actividad económica. Una vuelta atrás aterritorial, parece que producto de la crisis actual.

Sobre Ordenación del Territorio, concepto que en su significado expreso, no aparece tal cual en los textos analizados. Las escalas urbanísticas o intermedias (regionales propiamente dichas) no son en verdad, el propósito de estas obras, pero es muy significativo que no se encuentre ninguna referencia al interés, al menos, por la planificación física. Por tanto, la ordenación del territorio queda sepultada por la tozudez del Mercado y por su ineficiencia (planificación rígida y "pesada") tanto en épocas de bonanza económica, como en las actuales de necesidad de crecimiento a toda costa. A ello únase la arbitrariedad de los fallos y autos de la justicia tan distantes en sus sentencias, por parecidos motivos, en los litigios territoriales y urbanísticos. Es en las burbujas inmobiliarias, donde se roza tangencialmente, el interés por la ordenación del territorio, pero obviamente se explican por el excesivo apalancamiento de familias y empresas y el crecimiento inaudito de la deuda privada. Claves estructurales de las crisis bancarias contemporáneas. En los textos consultados se evita la ordenación del territorio, por inoperante en la explicación de los hechos económicos, casi ni para las grandes burbujas inmobiliarias; procesos prolíjamente analizados, como decimos, en las génesis de las crisis financieras. La planificación física no tiene sitio en un mundo donde sólo cabría regular (iOjalá!), la supervisión de los movimientos de capital, y utópicamente un impuesto anual sobre el capital. En general no hay lugar para la planificación, o por austeridad, o por necesidad de recuperar el crecimiento.

Por terminar, con una reflexión más política, de los "best-sellers" estudiados se deduce que vivimos un capitalismo, que como enseñó magistralmente y hace tiempo POLANY (1994), se ha desnaturalizado por completo el trabajo humano y los recursos naturales; incluso el papel del dinero. Tres cosas que no fueron creadas para ser compradas o vendidas pero que el capitalismo financiero ha convertido en simples mercancías que se utilizan con el único fin de que proporcionen beneficio; sin regulación de la avaricia desmedida o la codicia delictiva. De los textos se colige que en la economía actual se busca eliminar todo lo que signifique coste y merma de productividad para el capital. Así se acumula más extractiva y patrimonialmente, pero los seres humanos viven menos y peor.

\section{BIBLIOGRAFÍA}

Acemoglu, D. y Robinson, J.A. (2012) Por qué fracasan los países. Los orígenes del poder, la prosperidad y la pobreza, Ed. Deusto, Ed. Deusto, Barcelona, 588 pp. 
Banco Mundial (2008) Una nueva geografía económica. Informe sobre el desarrollo mundial 2009, Washington D.C. 48 pp.

Benko, G. y Lipietz, A. (1994) Las regiones que ganan, Ed. Alfons el Magnànim Valencia, $400 \mathrm{pp}$.

Bhattacharjea, A. (2010) "Did Kaldoranticípate New Economic Geography? Yes, but..." en Cambridge Journal of Economics, № 34, Cambridge, pp.1057-1074.

Bherens, K. y Thisse, J-F., "Regional Economics: A new economic geography perspective" en Regional Science \& Urban Economics, № 37, pp. 457-465.

Blaug, M. (1986) Great Ecnomist before Keynes, Cambridge University Press, USA, pp 565.

Buttler, J.H. (1996) Geografía Económica. Aspectos espaciales y ecológicos de la actividad económica, Ed. Limusa, México, 346 pp.

Cano, G. (1983) "Unidad y diversidad de la geografía andaluza" en Revista de Estudios Andaluces, № 1, pp. 9-22.

Castells, M. -dir.- (2001) La era de la información, (III vols.), Alianza Ed., Madrid, vol III, $484 \mathrm{pp}$.

Celis, F. (1988) Análisis Regional, Ed. de Ciencias Sociales, La Habana, 247 pp.

CEPAL (1990) Transformación Productiva con equidad. La tarea prioritaria del desarrollo de América Latina y El Caribe en los años noventa, Publicaciones de Naciones Unidas, Santiago de Chile, 1061 pp.

Cuadrado Roura, J.R. (2010) Política Económica. Elaboración, objetivos e instrumentos, Ed. McGraw-Hill, Madrid, 334 pp.

Cuadrado Roura, JR. (2012) ¿Es tan "Nueva" la "Nueva Geografía Económica"? Sus aportaciones, sus límites y su relación con las políticas, IAES, Universidad de Alcalá, Serie Documentos de Trabajo 01/2012, 37 pp.

Esping-Andersen, G. (1993) Los Tres mundos del Estado del Bienestar, Ed. Alfons el Magnànim, Valencia, 309 pp.

Fontana,J. (2011) Por el bien del Imperio. Historia del mundo desde 1945, Círculo de Lectores, Barcelona, $1242 \mathrm{pp}$.

Fujita, M. (2009) "New Economic Geography: an appraisal on the ocasion of Paul Krugman's 2008 Nobel rize Economic Sciences" en Regional Science and Urban Economics, № 39, USA, pp. 109-119. 
Fujita, M., Krugman, P. y Venables, A. (2000) Economía espacial. Las ciudades, las regiones y el comercio internacional, Ed. Labor, Barcelona, 386 pp.

Fujita, M. y Krugman, P. (2004) "La Nueva Geografía Económica: pasado, presente y futuro" en Investigaciones Regionales, № 4, Madrid, pp. 12-38.

Furió, E. (1996) Evolución y cambio en la economía regional, Ariel economía, Barcelona, $157 \mathrm{pp}$.

Garfield, S. (2013) En el mapa. De cómo el Mundo adquirió su aspecto, Ed. Taurus, Madrid. 473 pp.

Glaeser, E. (2011) El Triunfo de las ciudades, Ed. Taurus, Madrid 2011, 494 pp.

Haddad, P., Carvalho, C.M., Boisier, S. y Almeida, T. (1998) Economía Regional. Teorías e Métodos de Analise, Ed. BNB, Fortaleza, 694 pp.

Hessel, S. (2009) Indignaos, Ed. Destino, Madrid, 30 pp.

Hierro, L.A. (2011) Los ciudadanos por encima de los mercados, Punto Rojo libros, Sevilla, 218 pp.

Howitt, P. (2007) "Innovation, Competition and Growth: a schumpenterian perspective in Canada's economy" en Commentary CD, Howe Institute, № 246, Abril 2007, 19 pp.

Kaplan, R.D. (2013) La venganza de la Geografía, RBA editores, Barcelona 2013, 478 pp.

Krugman, P. (1999) El Teórico Accidental y otras noticias de la ciencia lúgubre, Ed. Crítica, Barcelona 1999, 194 pp.

Krugman, P. (2000) "Where in the World in the "New Economic Geography", en New Economic Geography, The Oxford Handbook of Economic Geography, Oxford University Press, Oxford (cap. 3).

Landes, D.S. (1999) La Riqueza y la Pobreza de las Naciones, Ed. Crítica, Barcelona, 604 pp.

Levitt, S.J. y Dubner, S.J. (2007) Freakonomics. Un economista políticamente incorrecto explora el lado oculto de lo que nos afecta, Ed. Zeta, Barcelona, pp. 325.

Marshall, A. (1990) Principles of Economics, McMillan, Londres, 234 pp.(Reproducción de su obra de 1890).

ISSN: 0212-8594 ISSN-e: 2340-2776.№ DOI: http://dx.doi.org/10.12795/rea.2015.i32.02 
Martín, R.L. (2010) "The New Economic Geography: credibles models of the economic landscape en A Compendium of Economic Geography, Ed. Sage, Londres 2010, 485 pp.

Myro, R. y Otros (2008) Globalización y deslocalización- Importancia y efectos para la industria española, Ministerio de Industria, Turismo y Comercio, Madrid, 187 pp.

Navarro, V. (2000) Globalización económica, poder político y Estado del bienestar, Ed. Ariel, Barcelona. 269 pp.

OCDE (2009) How Regions Grow, Paris, 149 pp.

Piketty, T. (2013) Le Capital au XXIe siècle, Ed. Seuil, Paris. 969 pp.

Polany, K. (1994) El sustento del hombre (incluye La Gran Transformación, texto de 1944), Ed. Mondadori, Barcelona. 225 pp.

Porter, M.E. (1991) The Competitive Advantage of Nations, Free Press, New York 1990 \&1998, 1025 pp. (Primera edición en español, Ed. Vergara, Buenos Aires 1991).

Przeworski, A. (1991) Democracia y Mercado, Cambridge University Press, USA 1991, $356 \mathrm{pp}$.

Reinhart, C.M., y Rogoff, K.S. (2011) Esta vez es distinto. Ocho siglos de necedad financiera, Fondo de Cultura Económica, México. 472 pp.

Richardson, H.W. (1975) Elementos de Economía Regional, Alianza Ed., Madrid. 346 pp.

Richardson, H.W. (1986) Economía regional y urbana, Alianza Universidad, Barcelona. $309 \mathrm{pp}$.

Rothkopf, D. (2008) El Club de los Elegidos. Cómo la élite del poder global gobierna el mundo, Ed. Tendencias, Barcelona. Pp.572.

Sassen,S. (2010) Territorio, autoridad y derechos: de los ensamblajes medievales a los ensamblajes globales, Ed. Katz, Buenos Aires. 599 pp.

Sen, A, y Kliksberg, B. (2007) Primero la gente, Ed. Deusto, Barcelona. 322 pp.

Stiglitz, J.(2002) El malestar de la globalización, Ed. Taurus, Madrid 2002, 314 pp.

Stiglitz, J. (2010) Caída libre. El libre mercado y el hundimiento de la economía mundial, Ed. Taurus, Madrid, pp. 423.

ISSN: 0212-8594 ISSN-e: 2340-2776.№ DOI: http://dx.doi.org/10.12795/rea.2015.i32.02 
Storper, M. (2011) "Why regions develop and change? He challenge for Georahy and Economics" en Journal of Ecnomic Geography, № 11, USA 2011, pp. 333-346.

Venables, A.J. (2007) "Evaluating urban transport improvements: cost-benefit analysis in the presence of agglomeration and income taxation" en Journal of Transport Economic and Policy, № 41, Año 2007, pp. 173-188.

Vázquez, A. (2007) “Desarrollo endógeno. Teoría y políticas de desarrollo territorial” en Investigaciones Regionales, № 11, Otoño 2007, pp. 183-213.

Viveret, P. (2004) Reconsiderar la riqueza y el empleo, Ed. Icaria, Madrid, 255 pp.

VV. AA. (2011) El Atlas de las Mundializaciones, Fundación Mondiplo, UNED, Le Monde, Valencia, $186 \mathrm{pp}$.

VV. AA. (2011) Journal of Economics Geography. Especial sobre la "Nueva" Geografía Económica. Número 11. USA. Marzo, 346 pp. 